\title{
DON QUIJOTE EN EL PACÍFICO: LA CONSTRUCCIÓN DEL PROYECTO ESPAÑOL EN ASIA, 1591-1606
}

\author{
LUIS ALONSO ÁLVAREZ \\ Universidad de A Coruña ${ }^{\mathrm{a}}$
}

\begin{abstract}
RESUMEN
El trabajo está estructurado en tres partes. En primer lugar, se identifica el proyecto que llevó a los españoles a instalarse en el Lejano Oriente en el último tercio del siglo xvi. Conocido éste, se analizan en segundo lugar los recursos con que contaba la Corona para sostener el proyecto y, finalmente, los incentivos que generó para estimular la instalación en las islas de colonos que asegurasen su continuidad, al menos hasta el último tercio del siglo xvIII. Las fuentes empleadas consisten básicamente en la contabilidad de la Hacienda filipina de finales del siglo xVI y primera mitad del xvII, las primitivas relaciones de la conquista (1575-1590) y las crónicas de comienzos del Seiscientos.
\end{abstract}

Palabras clave: hacienda pública, economía filipina, tributo indígena, imperio español en Asia

\section{ABSTRACT}

This paper is divided into three parts. In the first one we identify the project that led the Spaniards to settle in the Far East in the last third of the sixteenth

\footnotetext{
${ }^{a}$ Departamento de Economía Aplicada I. Facultad de Ciencias Económicas y Empresariales. Campus de Elviña, s/n. 15075 A Coruña. alvarez@udc.es
} 
century. In the second, we analyse the resources that the Spanish Crown counted on in order to support the project. And, finally, the incentives that the latter generated to stimulate the installation in the islands of settlers that assured their continuity, at least until the last third of the eighteenth century, are also studied. The sources used are basically the accounts of the Philippine Treasury of the late sixteenth century and first half of the seventeenth century, the primitive 'relaciones' of the conquest (1575-1590) and the 'crónicas' of the early sixteenth century.

Keywords: Public Treasury, Philippine economy, Indigenous tax, Spanish Empire in Asia

JEL Classification: N45, N95 y N55

\section{INTRODUCCIÓN}

Las islas Filipinas -la presencia española más notable en el Pacífico asiático entre los siglos XVI y XIX-, no solo fueron conquistadas en tiempo en que Cervantes perfilaba las hazañas del Caballero de la Triste Figura, sino que su proyecto de colonización respondió en alguna de sus formulaciones a una quimera quijotesca, cuya leyenda tejieron aquellas palabras del Rey Prudente, que el clero más belicoso había puesto en sus labios: «bastaría con que hubiera allí [en las islas Filipinas] una sola persona que sostuviera el nombre y la veneración de Jesucristo para que enviara todas las rentas de España a difundir el Evangelio». Uno de los primeros historiadores contemporáneos en destacar el carácter utópico de la colonización filipina fue el hispanista francés Pierre Chaunu al señalar que «Don Quichotte et Sainte-Thérèse [esto es, el guerrero y el clérigo idealistas] rendent mieux compte que la balance des payements des Philippines espagnoles». Para aclarar de inmediato que «les Philippines ont coûté à l'Espagne, à la belle époque, 10 à 15\% environ de ce que pouvaient lui rapporter les Indes» ${ }^{1}$. Se trata de una hipótesis cuando menos discutible, como he tratado de destacar en otras ocasiones al analizar las cifras de su Hacienda², por lo que conviene no olvidar el papel destacado que desempeñó Sancho en el gobierno de aquella singular Ínsula de Barataria.

En lo que sigue, estructuraré el ensayo en tres partes. En primer lugar, identificaré el proyecto que llevó a los españoles a instalarse en el lejano Pacífico. Conocido esto, destacaré los recursos con que contaron para sostener el proyecto y, finalmente, subrayaré el incentivo que generaron para estimular el establecimiento en las islas de colonos que asegurasen su lealtad a la Corona. Las fuentes em-

\footnotetext{
${ }^{1}$ Chaunu (1960), p. 268.

2 Alonso Álvarez (2003a).
} 
DON QUIIJOTE EN EL PACÍFICO: LA CONSTRUCCIÓN DEL PROYECTO ESPAÑOL EN ASIA...

pleadas, que se incluyen detalladas en las páginas finales, se apoyan básicamente en la contabilidad de la Hacienda filipina de finales del siglo xvı y primera mitad del XVII, las primitivas relaciones de la conquista (1575-1606) y las crónicas de comienzos del seiscientos. Frente a estas dos últimas, no se conocen fuentes alternativas de procedencia indígena.

\section{EL PROYECTO ESPAÑOL EN ASIA}

El proyecto español en Filipinas presenta objetivos cambiantes en el tiempo, a veces solapados y con frecuentes avances y retrocesos que dificultan un análisis lineal. Durante la época de Carlos I, la Corona pretendió competir por el control del mercado europeo de las especias, dominado entonces por los portugueses. De este modo, la creación de un Imperio español de la Pimienta estuvo en la base de las frustradas expediciones de Fernando de Magallanes (1519) y Jofre de Loaysa (1525), financiadas desde España, de las de Álvaro de Saavedra (1527) y Ruy López de Villalobos (1542), proyectadas desde México y, finalmente, de la de Miguel López de Legazpi (1565), la única en alcanzar plenamente sus objetivos. En la propia Instrucción que la Audiencia de México -en ausencia del Virrey don Luis de Velasco el Viejo, recién fallecido- despachó a Legazpi se subrayaban éstos claramente: «Haréis vuestra navegación en demanda y descubrimiento de las islas del Poniente [...], que diz que tienen también especia». Al tiempo, se señalaban algunos particulares sobre la forma en que habrían de conducirse en la contratación ${ }^{3}$.

Sin embargo, esta primitiva pretensión fue muy pronto abandonada por dos razones. En primer lugar, porque no se encontró la más estimada de las especias, la pimienta. Por el contrario, era la canela la única que las Islas producían con cierta abundancia, pero se encontraba en Mindanao -véase el mapa del final-, un área de influencia de los indígenas islamizados del sur, muy hostiles a la hispanización. Legazpi envió algunas muestras del fruto a México en 1565 y 1567, pero obtuvo escasos resultados comerciales ${ }^{4}$. Por todo ello, escribía en 1569 al virrey en estos términos:

«Antes de agora é escrito que si su majestad no pretende más de solas estas yslas felipinas, se debe azer poco caso dellas, porque al presente no se puede sacar de aquí sino sólo canela que sea de provecho, y hasta dar orden y asiento en ella no podrá su magestad dexar de gastar dineros» ${ }^{5}$.

${ }^{3}$ AGI, Patronato, 23, Ramo $12^{\circ}$. Reproducida en Hidalgo Nuchera (1995), p. 113. Puede verse también, entre otros, en Academia [Española] de la Historia (1886), p. 161 y en Rodríguez (1978), pp. 326-372. El subrayado es mío. En los textos literales, se respeta la grafía de finales del siglo XVI.

${ }^{4}$ García-Abásolo (1982), p. 65.

${ }^{5}$ Rodríguez (1978), p. 21. 
En 1572, poco antes de su muerte, Legazpi enumeraba ante la autoridad novohispana los productos de la tierra que podían disponer de ventajas comerciales en América y España, pero significativamente no incluía ya entre ellos las especias, ni siquiera la que abundaba en el sur, la canela: «Lo que desta tierra podrán llevar de retorno [las naos] es mantas de algodón, çera y hilo y algún oro, y andando el tiempo se engrosará la contratación de los chinos» ${ }^{6}$.

El abandono del proyecto de las especias quedó certificado cuando los dos estados ibéricos dejaron de ser competidores, al unirse sus destinos en la Corona de Felipe iı en 1580. Es, pues, en la década de los 80 cuando se reformularon los objetivos españoles en las islas: la creación -o ampliación- de un Imperio asiático, en paralelo al Imperio americano. Esto explica los intentos de conquista y expansión del territorio filipino a las islas colindantes. Podemos precisar que el nuevo proyecto comenzó en 1578 con la expedición a Borneo del gobernador Francisco de Sande (1576-1580) y finalizó de una manera dramática en 1593 con la muerte de Gómez Pérez Dasmariñas (1590-1593) cuando partía a la reconquista de Terrenate, antiguo asentamiento portugués. Sin embargo, asociado a todo ello emergió el descabellado intento de la conquista de China, en aquellos momentos sin duda la gran potencia mundial, tanto considerada en el plano militar como tecnológico y cultural $^{7}$. Inducido por militares en busca de honores $\mathrm{y}$, sobre todo, por algunos de los religiosos regulares a quienes la práctica de la imposición del tributo indígena, como veremos, no parecía compatible con la de la moral cristiana, a la vez que buscaban una alternativa misionera en otras áreas, el rey Felipe in había enviado a algunos agentes al Imperio Celeste -entre ellos el agustino Martín de Rada en los 70 y el jesuita Alonso Sánchez en los 80- en busca de información de primera mano sobre sus recursos y sus gentes. En este sentido, muchos de las cartas e informes de los frailes regulares a organismos oficiales reflejaban esta idea. El propio Martín de Rada recomendaba al Virrey en 1569 la ocupación plena de las islas Filipinas como paso previo a la conquista de China, una quimera que entendía practicable:

«Si su majestad pretende la china, ques tierra muy larga, rrica y de gran poliçía, que tiene ciudades fuertes y muradas, muy mayores que las de Europa, tiene necesidad primero de azer asiento en estas islas [Filipinas]; lo vno, porque no sería azertado pasar por entre tantas yslas y baxíos, como ay a la costa della, con navíos de alto bordo sino con navíos de rremos; lo otro tanbién, porque para conquistar vna tierra tan grande y de tanta gente, es necesario tener çerca el socorro y acogida para qualquier caso que sucediere, avnque según me é informado [...], la gente de china no es nada belicosa y

\footnotetext{
${ }^{6}$ Hidalgo (1995), p. 311 y Rodríguez (1978), p. 129.

${ }^{7}$ Ollé (2000).
} 
toda su confiança está en la multitud de la gente y en la fortaleça de las murallas, lo qual sería su degolladero, si se les tomase alguna, y así creo que mediante dios fácilmente, y no con mucha gente, serán sujetados» ${ }^{8}$.

Resulta también muy significativo el contenido de una carta del propio Legazpi al monarca en 1570, cuando, convencido ya de que las islas no disponían de especias comerciales, nos desvelaba que el futuro establecimiento de los españoles en Manila, al norte del archipiélago, les dotaría de la base mejor situada, en términos estratégicos, para el acceso al continente asiático, del mismo modo que las Antillas habían sido utilizadas para el salto al continente americano: «Si su majestad pretende que sus ministros se estiendan a la parte del norte y costa de china, tengo por más açertado hazer asiento en la isla de luçón» ${ }^{9}$. Hasta tal punto estaban decididos los militares hispano-mexicanos a disponerse en pie de guerra que en 1576 el gobernador Sande se brindaba al rey para encabezar la conquista del continente: "Yo me ofresco de seruir a V.M. en esta jornada, y la deseo tanto que no lo sé encarescer ${ }^{10}$. Sin embargo, una circunstancia novedosa provocó un nuevo replanteamiento de la estrategia de la presencia en Filipinas: la dificultad de disponer de recursos suficientes para armar una gran flota de guerra tras la derrota de la Invencible en 1788. En los primeros noventa, en carta al obispo Salazar, la Corona parece descartar ya la idea del Imperio asiático al prohibir a los religiosos el desplazamiento al continente ${ }^{11}$.

Fracasados los intentos anteriores acabó imponiéndose, así, desde comienzos del siglo XVII el objetivo de unas Filipinas como flanco occidental para la defensa del Imperio americano. Pero esto no debe entenderse tanto como efecto de la disuasión -las Filipinas estaban demasiado alejadas de América- como porque obligaba a los competidores del Imperio, sobre todo a los holandeses, a ejecutar un gasto militar respetable en Asia que, de ese modo, no sería realizado en América, lo único realmente valioso en términos de producción de plata. Como señalaría en 1736 el Procurador General de las Islas en la Corte, don Juan Grau y Monfalcón en su Memorial al Rey, «la conservación de las islas [es] el medio más eficaz para la conservación de todos los estados que esta Corona tienen en la India oriental y partes adyacentes, y por consiguiente de las Occidentales» ${ }^{12}$. Para ello era fundamental hostigar y obstaculizar el comercio holandés, obligándole a invertir en fortalezas, presidios y armadas. Ocupados en la defensa de sus territorios y bases en Asia, no dispondrían de tantos recursos para agredir a las

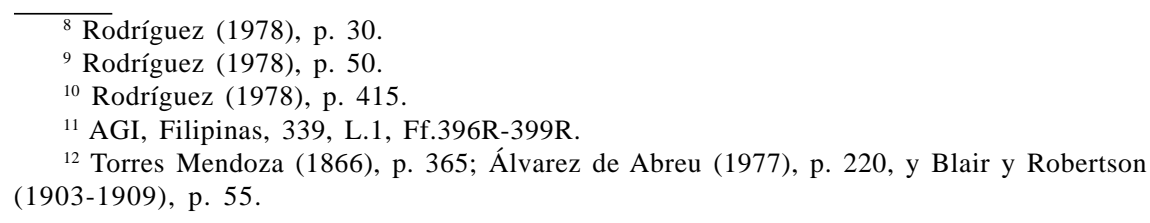


colonias de América. Para el Imperio español, el gasto ejecutado en Asia se justificaba, así, por el alto coste de oportunidad que tendría en América el no practicarlo. Como resumía el Procurador General mencionado, las Filipinas servían a la Corona para

«quitar mucha parte del comercio a los holandeses, no solo con sustentarle España en las Filipinas, que a faltar, fuera todo suyo, según queda declarado, sino con obligarle que para conservar el que ha usurpado, tenga los presidios y armadas que se han referido, con que siendo los gastos mayores, es forzoso que sean menores las ganancias; [y al tiempo] aliviar las Indias Occidentales que con la diversión y gasto que el enemigo tiene en las Orientales y plazas del Maluco es forzoso acudir menos y con menos fuerza a infestarlas» ${ }^{13}$.

Este proyecto u objetivo de actuación política de la Corona en las islas se mantuvo prácticamente invariable en el largo plazo. Estuvo vigente, sin grandes modificaciones, durante el siglo XVII y gran parte del XVIII. Quebró, sin embargo, en 1762 con la toma británica de Manila, dando origen a un conjunto de transformaciones puestas en marcha por el reformismo borbónico -reformuladas en el siglo xIx bajo administración liberal-, y en las que obviamente no entraré.

\section{RECURSOS PÚBLICOS PARA SOSTENER EL PROYECTO}

Aclarada ya la cuestión de qué hacían los españoles en Asia, responderé ahora a la segunda: con qué recursos pudieron sostener sus objetivos. En la Instrucción a Legazpi, dada por la Audiencia novohispana en 1564, se indicaba que las Cajas de México facilitarían la financiación de la armada compuesta por dos navíos de mayor calado y dos embarcaciones auxiliares. Se dotaba además a las naves de un número de soldados y marinos y de armas, municiones, pertrechos y alimentos para la travesía. Se enviaban también «rescates y mercaderías» propiedad de la Corona, de todo lo cual habían de tener «cuenta y razón» los oficiales reales -tesorero, contador y factor-, que debían disponer de un libro en donde anotar lo que hubiesen de ingresar y pagar ${ }^{14}$. Tenemos, pues, constituida formalmente la Hacienda filipina con tres oficiales reales y un libro de registro, en donde se habrían de inscribir los ingresos iniciales, configurados por el valor de los navíos, armamento, abastos y alimentos, únicos asientos disponibles hasta aquellos mo-

\footnotetext{
${ }^{13}$ Torres Mendoza (1866), p. 411.

${ }_{14}$ AGI, Patronato, 23, Ramo $12^{\circ}$. Reproducido por Hidalgo Nuchera (1995), p.107; Rodríguez (1978), p. 326, y Academia [Española] de la Historia (1886), p. 145.
} 
DON QUIIJOTE EN EL PACÍFICO: LA CONSTRUCCIÓN DEL PROYECTO ESPAÑOL EN ASIA...

mentos de un Erario público que ni siquiera disponía aún de contribuyentes ni, mucho menos, de dominio fiscal.

Pero muy pronto, los recursos anotados en el libro de registro resultaron insuficientes al poco de arribar las huestes de Legazpi a la isla de Cebú, la primera que alcanzaron los expedicionarios. En efecto, nada más desembarcar surgieron los primeros problemas. No sólo no fueron bien recibidos por los isleños, sino que muchos de los campesinos que poblaban Cebú y las islas adyacentes manifestaron una decidida hostilidad hacia los recién llegados. En la medida en que los pertrechos y alimentos traídos de México se fueron consumiendo, y ante las dificultades reales para reponerlos, llegó a peligrar la continuidad de la empresa. Frente a los hispano-mexicanos, los campesinos indígenas habían adoptado la estrategia del abandono de los campos de cultivo, esperando rendirles por necesidad y por hambre. Sobre esta cuestión, existen numerosos testimonios contemporáneos. Uno de los más antiguos está contenido en la relación del agustino Diego de Herrera en carta enviada a Felipe ir desde México en 1570, a sólo cinco años del desembarco inicial:

«La gente que allá quedó ha pasado todo este tiempo muy graves necesidades, con ser la tierra muy abundante, porque no se pudo tomar asiento tan pacíficamente que no fuese contra la voluntad de los naturales, y así se alborotaron y muchos se huyeron y desampararon sus pueblos, y los que quedaron se determinaron de no beneficiar sus sementeras ni sembrar, creyendo con este ardid de guerra poder echarnos de su tierra; a cuya causa ellos y nosotros hemos padecido necesidades grandes» ${ }^{15}$.

La misma idea subyacía en el texto de Miguel de Benavides, primer Obispo de Manila, cuando señalaba algunos años más tarde:

«Visto que los españoles quedaban poblados en la tierra y no con trato y traje de mercaderes, sino de soldados, pensaron [los naturales] cómo poderlos echar de ella y acordaron que por hambre los echarían mejor que por guerra; y así se pusieron en toda la tierra a no sembrar» ${ }^{16}$.

La respuesta de Legazpi, tras consultar con sus oficiales, fue poner en marcha la terrible maquinaria de la entrada. La entrada consistía en una táctica militar que comportaba el asalto de las poblaciones a sangre y fuego. Así nos la relataron las primitivas relaciones:

«Visto por los españoles la falta de la comida, y que los indios no sembraban, y que donde la había la llevaban tierra adentro, para buscar la

\footnotetext{
${ }^{15}$ AGI, Patronato 24, Ro 16. Reproducido en Rodríguez (1978), p. 38.

${ }^{16}$ Benavides (c. 1595), p. 202.
} 
comida se tenía esta orden. Salía una compañía de españoles e iban a un pueblo y estaban toda una noche sobre él, y al amanecer daban en él y mataban muchos indios y los robaban las haciendas y les cautivaban sus hijos y mujeres y les tomaban la comida que en el pueblo había. De esta manera se gobernó aquello por algún tiempo» ${ }^{17}$.

La frecuencia e intensidad de las entradas obligaron a los campesinos a negociar, lo que se concretó en un intercambio de presentes, la venta de alimentos y una promesa de amistad que fueron considerados de manera desigual por las partes en conflicto. Mientras que los líderes indígenas confiaban en que aquello haría reconsiderar su permanencia a los recién llegados, éstos vieron en la nueva posición de sus adversarios un símbolo de reconocimiento de soberanía que facultaba el derecho a exigirles un gravamen. Así lo atestigua el propio Obispo Benavides:

«Viendo mucha parte de los indios la mala orden que los españoles tenían, y que no les dejaban estar seguros en sus casas, acordaron de venir al gobernador [Legazpi] y decir que ellos querían ser amigos de los españoles, por que los dejasen estar seguros en sus casas y que no les hiciesen el mal que habían hecho a los demás sus vecinos. Así quedaban éstos por amigos; y hase de entender que el quedar por amigos de los españoles era quedar por sus vasallos tributarios» ${ }^{18}$.

Este es el origen histórico del gravamen fiscal impuesto por los españoles en las islas Filipinas que apuntaló sus objetivos de permanencia, el tributo indíge$n a$, pero casi de inmediato emergieron las ventas forzadas de alimentos y pertrechos -los llamados en México repartimientos de dinero, bandalas en el área tagala- y las prestaciones obligatorias de servicios o polos ${ }^{19}$.

El tributo indígena se caracterizaba en esta época inicial por una imprecisión en la cuota y por ser de naturaleza arbitraria y coactiva. Las autoridades ignoraban la cuantía de los tributos a ingresar porque desconocían el número de pueblos y campesinos sometidos. El testimonio más antiguo de que disponemos sobre el valor del gravamen data de 1573 y es obra de Hernando Riquel, escribano de gobernación, para quien suponía el pago anual de una manta listada de cuatro varas de largo y dos de ancho y una gallina ${ }^{20}$. Un año después, el agustino Martín de Rada lo evaluaba en una manta de dos varas de largo y una de ancho, dos fanegas de arroz y, en defecto de estos productos, tres maes de oro, que equiva-

\footnotetext{
${ }^{17}$ Ibidem.

${ }^{18}$ Ibidem. El subrayado es mío.

${ }^{19}$ Alonso Álvarez (2000) y (2003b).

${ }^{20}$ Hidalgo Nuchera (1992), p. 35.
} 
lían a 7,5 reales de plata ${ }^{21}$. Ese mismo año, el gobernador interino y antiguo tesorero de la Hacienda, Guido de Labezaris, lo valoraba en dos fanegas de arroz sin descascarillar y una manta de dos varas de largo por una de ancho o en su defecto tres maes de oro o productos de la tierra por ese valor ${ }^{22}$.

Con todo, acabó por imponerse el pago de ocho reales por familia y año, realizado en especie, lo que parece una cuota muy baja si la comparamos con el gravamen de México y Perú ${ }^{3}$. Sin embargo, en la práctica el tributo suponía mucho más. Y la clave estaba en la tasación de los productos que lo conformaban, que había sido realizada por Legazpi y resultaba muy baja. La cláusula se manifestó muy eficaz en el momento en que comenzaron a revalorizarse los productos filipinos por una mayor demanda y más adelante, como veremos, por efecto de la inflación de la plata mexicana. De ese modo y conforme avanzaba la conquista, se produjo una distancia creciente entre los precios de tasación y los que marcaba el mercado, lo que explicaría la subida real del tributo, de manera que, en los momentos de mayor alza de los precios, los ocho reales de plata podían convertirse en más de treinta.

Esto nos conduce a considerar algunas de las restantes características del tributo primitivo: la arbitrariedad, coacción y violencia desplegadas en su recaudación por los encomenderos, militares beneficiados por la Corona en la cesión del gravamen. En 1572 el agustino Francisco Ortega escribía al virrey novohispano lo siguiente:

«Y es bien que V. Excelencia sepa el modo que en cobrar estos tributos se tiene, y cómo antes de tiempo se les pide, sin guardar ley de Dios ni instrucción de su Majestad; lo que hacen en llegando a cualquier pueblo o provincia es enviar un naguatato [intérprete] o dos, no con dádivas ni presentes, ni a predicarles ni decirles cosas de Dios, sino a decirles que traigan luego tributo y que sean amigos de los castillas; y como es cosa tan nueva y peregrina para ellos por no lo haber acostumbrado entre sí [...] háceseles muy de mal dar en tributo las cadenillas que traen en los cuellos, y las manillas que traen en los brazos [...] y como [...] rehúsan algunos el darlo [...], desamparan sus casas y van a los tingües y serranías, lo cual viendo los españoles, van tras ellos tirándoles arcabuzazos y matando cuantos pueden sin ninguna piedad, y vuelven al pueblo y matan cuantas gallinas y puercos hallan, y tomándoles todo el arroz, que los miserables

\footnotetext{
${ }^{21}$ AGI, Patronato, 24, Ro 29. En Rodríguez (1978), p. 190.

${ }^{22}$ AGI, Patronato 24, R ${ }^{\circ}$ 29. En Rodríguez (1978), p. 213.

${ }^{23}$ El peruano resultaba el tributo más elevado del Imperio. Según las tasas del Virrey Toledo, se situaba entre los 5 y los 6 pesos y su pago se exigía en plata ensayada y marcada o en oro fino. Véase Escobedo Mansilla (1979), p. 66. El contribuyente novohispano pagaba un peso de oro y media hanega de maíz, lo que en conjunto equivalía a unos dos pesos de plata ensayada. Véase al respecto Miranda (1952), pp. 169 y 269.
} 
tenían para su sustentación, y después de esto y de haberles robado todo lo que tienen en sus pobres casas, pónenles fuego, y de esta manera quemaron y abrasaron más de cuatro mil en esta jornada de Ilocos» ${ }^{24}$.

La arbitrariedad y la coacción en el cobro del tributo fue reconocida incluso por la misma Corona de manera muy explícita años después. Señalaba Felipe II:

«Asimismo he sido informado que en el cobramiento de los tributos de los indios ha habido por lo pasado, y hay al presente, mucha desorden a causa de que los gobernadores que han sido de las dichas Islas hicieron las tasas muy confusas; [de lo que] se tomó ocasión para la dicha desorden de cobrar cada uno como quiere, con grande escándalo y agravio de los dichos Indios» ${ }^{25}$.

Otro de los mecanismos de financiación de la Hacienda pública, aunque no aparecía asentado en las cuentas oficiales, estuvo conformado por las ventas forzadas de mercancías. Se trataba de una práctica novohispana, importada por los hispano-mexicanos que participaron en la conquista. En México estos tipos de ventas forzadas recibían el nombre de repartimientos de dinero, mientras que en el área tagala se conocían con la denominación de bandalas y se extendieron rápidamente debido a la necesidad que existía entre los españoles de alimentos y pertrechos. El campesino indígena había de vender a precio de arancel a los oficiales reales los productos demandados, especialmente el arroz para la alimentación de la tropa y determinados insumos para la construcción y apresto de los navíos que regresaban a México, el embrión de lo que más adelante sería el galeón de Acapulco. Como mecanismo fiscal, pues, las bandalas funcionaban de manera semejante al tributo al adquirirse a precios de arancel e ingresar el Tesoro la diferencia existente con los precios de mercado.

El tercer elemento que componía el complejo tributario de la primera Hacienda filipina estaba conformado por las prestaciones de servicios, los llamados polos en el área tagala. Como figura jurídica, el polo mantenía una gran semejanza con el cuatequil azteca y la mita peruana. Administrados de manera arbitraria -alguna de sus modalidades era retribuida a precios muy bajos, inferiores también a los de mercado-, los polos sirvieron, en ausencia de producción minera significativa, para vincular más fuertemente a la población indígena a la economía agraria intensiva, impuesta por los conquistadores y de la que hablaremos más adelante. En la contabilidad de las Cajas reales tan sólo aparecen reflejados parcialmente en el asien-

${ }^{24}$ AGI, Patronato 24, Ro 27. Cfr. Rodríguez (1978), pp. 137-8. En Filipinas se denominaba castillas o castilas a todos los hispano-mexicanos, una expresión que se mantuvo en el lenguaje coloquial hasta 1898.

${ }^{25}$ Cédula Real con Instrucción de 9 de Agosto de 1589. AGI, Filipinas, leg. 339, L.1, Ff.365V-389R. 
to denominado dinero remitido, en este caso destinado casi en exclusiva al pago de una de estas prestaciones, la más aborrecida por los campesinos filipinos: los cortes de maderas para la construcción de navíos en los bosques próximos al enclave de Manila. En general, podemos concluir que la generalización del complejo tributario a gran parte de las Visayas permitió la continuidad de la conquista, en especial la toma de Manila, lo que a su vez hizo posible la extensión de la obligación fiscal a la planicie de Luzón, la más relevante en términos estratégicos y económicos.

\section{CUADRO 1}

INGRESOS DE LA HACIENDA FILIPINA EN 1584 Y 1588 (EN PESOS DE A 8 REALES Y PORCENTAJES)

\begin{tabular}{|l|r|r|r|r|}
\hline & \multicolumn{2}{|c|}{ Año 1584 } & \multicolumn{2}{c|}{ Año 1588 } \\
\hline Tributo indígena & 22.000 & 66,6 & 30.404 & 50,6 \\
\hline Diezmos del oro & 4.000 & 12,1 & 3.909 & 6,5 \\
\hline Derechos de almojarifazgo & 6.000 & 18,1 & 18.174 & 30,2 \\
\hline Justicia y estrados & 1.000 & 3,0 & 1.274 & 2,1 \\
\hline Extraordinario & - & - & 4.352 & 7,2 \\
\hline Penas de cámara & - & - & 1.884 & 3,1 \\
\hline Totales & $\mathbf{3 3 . 0 0 0}$ & $\mathbf{1 0 0 , 0}$ & $\mathbf{5 9 . 9 9 7}$ & $\mathbf{1 0 0 , 0}$ \\
\hline
\end{tabular}

Fuente: AGI, Contaduría, leg. 1200

El Cuadro 1 pone de manifiesto cómo el tributo indígena era el gravamen de mayor dimensión, entre los dos tercios y la mitad de lo recaudado. El resto de los ingresos que componían la primitiva Hacienda real carecieron de relevancia, salvo los derechos de almojarifazgo, con tendencia a crecer conforme se asentaba el papel de la nao de Acapulco, de la que hablaré más adelante. Por su parte, los diezmos del oro, cuya cobranza resultó inicialmente de importancia -en 1584 alcanzó algo más del 12 por cien de los ingresos-, observaron un comportamiento inverso, al extinguirse en pocos años la cantidad de oro desviada a los conquistadores en forma de joyas, estatuillas y amuletos que los campesinos indígenas habían acumulado en el largo plazo.

Pero la recaudación del tributo no siempre fue fácil para los españoles por la hostilidad de los campesinos indígenas, la práctica inexistencia de una Administración proporcionada a la dimensión de las provincias en que se dividieron las 
islas y, sobre todo, por la fuerte dispersión del hábitat en barangays $^{26}$. Por ello hubieron de buscar colaboradores para completar sus insuficiencias. Y los encontraron, desde el primer momento, en el clero regular llegado a las Islas para acometer las funciones de evangelización, que puso en marcha la política de doctrinas y, más adelante, en la integración de los señores naturales en el proyecto español.

Los cronistas nos han dejado testimonios de la manera en cómo los frailes realizaban una doctrina, también denominada reducción o pueblo de indios, ese proceso de concentración, inicialmente con objetivo religioso, de la población dispersa desarrollado por primera vez en América ${ }^{27}$. Se trata de la practicada por el franciscano Juan de Plasencia, en Laguna, una de las primeras provincias, al sur de Manila, que comenzaron a poblarse, al disponer de una agricultura más intensiva -el cultivo del arroz por inmersión- que facilitó una mayor concentración de población. Allí nuestro fraile

«organizó los antiguos barangais de indios en las playas, para lo cual mandó construir en cada uno de ellos un tugurio de caña y nipa que sirviese de templo, y junto a él una pequeña vivienda para el misionero. Dividió luego la gente por familias y nombró a uno de los indios más aptos por cabeza de barangay, que equivalía al cargo de alcalde de barrio de los municipios Españoles» ${ }^{28}$.

El Obispo Benavides nos describe cómo se tomaba la decisión de poblar, de común acuerdo entre el alcalde mayor de la provincia y el cura doctrinero:

«Tenga por fin prinçipal el Alcalde mayor el serviçio de Dios y el buen tramiento de los yndios [...]; tenga cuydados [que] en su districto aya divission de Barangayes. Y si estuvieren los yndios muy divididos, procure con suavidad juntarlos a poblaçiones y doctrinas con la menor costa suya que ser pudiere y con pareçer del ministro para que assí sean mejor doctrinados, y se eviten ydolatrias y otros pecados, lo cual debe procurar como quiera que sea» ${ }^{29}$.

${ }^{26}$ Las unidades de poblamiento, los denominados barangays, se encontraban diseminados por la floresta, estaban conformados por un número de familias que oscilaba entre la treintena y el centenar, que disponían de autonomía económica y política, y eran gobernados por un datu. La palabra barangay tiene un origen marino y hace alusión a los navíos (barangays) en los que los pobladores malayos de las Filipinas, que procedían de Indonesia y del continente, llegaron a las islas en distintas oleadas migratorias en los siglos anteriores a la era cristiana. Cada navío era gobernado por un cabeza, según expresión española, de la que deriva el nombre de cabeza de barangay y que alude a la aristocracia indígena, los señores naturales de las islas. Véase Alonso Álvarez (2005).

${ }^{27}$ Los tres expresiones se emplearon de manera indistinta para denominar una misma realidad, que era el agrupamiento de barangays dispersos en un nuevo poblamiento de mayor densidad. El término doctrina expresaba un contenido netamente religioso -los campesinos indígenas estaban reunidos en agrupaciones para su adoctrinamiento-, mientras que los de reducción y pueblo de indios conservaban un significado laico, militar en el primer caso y civil en el segundo.

${ }^{28}$ Pastells (1926), p. ccxviii.

${ }^{29}$ Benavides (c. 1595), p. 186. 
DON QUIIJOTE EN EL PACÍFICO: LA CONSTRUCCIÓN DEL PROYECTO ESPAÑOL EN ASIA...

Aunque el grueso de las reducciones no comenzó a practicarse hasta los primeros 90, tras la Instrucción de Felipe II al gobernador Dasmariñas, los franciscanos se habían anticipado en una década, como vimos, en la fértil área de Laguna, uno de los escasos espacios de la llanura de Luzón en que era posible el cultivo intensivo del arroz por irrigación y, por lo tanto, la de mayor concentración demográfica. El capítulo provincial franciscano de 1580, presidido por Juan de Plasencia, instó a los doctrineros a fijar su residencia entre los campesinos indígenas, con orden de construir iglesia y convento, acordándose «activar la reducción de indios a pueblos»: «Así redujeron a poblados los franciscanos los numerosos indios diseminados por los bosques». El propio Juan de Plasencia había fundado 16 pueblos de indios en la provincia de Laguna. En el capítulo provincial de 1583, celebrado en Manila y en el cual fue nombrado superior, se aprobó la creación de 25 doctrinas, todas ellas al sur de la isla de Luzón. Plasencia escribió además al Gobernador y al monarca para que se obligase a los campesinos a vivir en pueblos $^{30}$. De ese modo, reunida la población en espacios más amplios, fue posible el cobro del tributo -la piedra angular de la Hacienda filipina que permitió financiar el proceso de hispanización- y, en paralelo, la adaptación de cultivos que producían mayores rendimientos para una población más concentrada a partir de la renovación del utillaje agrícola ${ }^{31}$.

Fueron también los misioneros los que introdujeron en sus doctrinas las dos mayores innovaciones tecnológicas en el utillaje agrícola: el arado chino -que acabó substituyendo al palo agrícola (bacol) - y el carabao o buey asiático como animal de tracción. Ambas innovaciones difundieron el cultivo del arroz por irrigación, frente al de secano dominante (slash-and-burn). El religioso era el primero en arar y sembrar, lo que resultaba una atracción para los campesinos que bajaban de sus barangays, facilitaba su adoctrinamiento e integración y aumentaba la autonomía alimenticia de los nuevos asentamientos. No obstante, la introducción de cultivos intensivos hizo crecer la presión de la demanda sobre la tierra y facilitó la generalización de la propiedad privada de los campos de arroz ${ }^{32}$. Hasta entonces, en un contexto de agricultura poco intensiva, la tierra no resultaba el factor de producción fundamental, porque abundaba, sino que lo era el trabajo, que escaseaba. Por esa razón, entre los filipinos primitivos solo existía la propiedad privada sobre el trabajo, a través de la figura jurídica de la esclavitud, pero no sobre la tierra. A partir de la generalización del sistema de doctrinas, que concentró población, se devaluó el factor trabajo pero se revalorizó el de la tierra. Y en la medida en que ahora era ya la tierra el factor fundamental, el Consejo de Indias determinó prohibir la esclavitud, lo que aceleró aún más el proceso de intensifica-

\footnotetext{
${ }^{30}$ Pastells (1926), p. ccxviii.

${ }^{31}$ Corpuz (1997), p. 28.

32 Zialzita (2001), p. 121.
} 
ción de la agricultura de las lowlands. Estas innovaciones tecnológicas con sus derivadas económicas y sociales permitieron suplir la caída de la mano de obra provocada por la conquista e incrementar la productividad primaria, con lo que los campesinos indígenas pudieron satisfacer de manera generalizada sus obligaciones fiscales. Asimismo, lograron desarrollar excedente en cantidad suficiente como para conducirlo al mercado de Manila y, conforme avanzaba la centuria, a los centros mineros y urbanos de la Nueva España tras la consolidación de la economía del galeón ${ }^{33}$. Sin embargo, en todo este complejo proceso resultó fundamental, además de la figura de los religiosos, el papel desplegado por los señores del barangay, como veremos de inmediato.

Los señores naturales de los campesinos indígenas habían sido separados de sus señoríos en los momentos iniciales de la conquista, repitiendo en gran medida la cruel experiencia mexicana que habían vivido muchos de los militares llegados a las islas. De ello se hacía eco la Real cédula de 11 de junio de 1594 expedida por Felipe II, quien señalaba haber «sido informado que los indios principales de esas Islas están destituidos del señorío que tenían en su gentilidad, y aquél enajenado y puesto en vasallos que eran suyos» ${ }^{34}$.

Sin embargo, difícilmente podían funcionar las reducciones y afianzarse el cobro de tributos sin la incorporación de los caciques primitivos -cuya influencia sobre sus súbditos era manifiesta- al proyecto español. Por lo que, en los primeros noventa, se va a producir un cambio radical de estrategia que pasaba por la conservación de las antiguas estructuras de poder, cuyos argumentos resume el documento anterior:

«Porque no es justo que [los señores naturales] sean de peor condición después de haberse convertido, antes se les haga tratamiento que los aficione y mantenga en fidelidad, de manera que con los bienes espirituales que Dios les ha hecho de llamarlos a su verdadero conocimiento se junten los temporales y por todo vivan con contentamiento» ${ }^{35}$.

Por todo ello, el Rey instaba a las autoridades de las islas a

«que â estos tales les hagais buen tratamiento, y les encomendeis en mi nombre el Govierno de los Indios de que eran señores, y que en todo lo demas procureis justamente su aprovechamiento, haciendoles los Indios algún reconocimiento en la forma que lo hacian en tiempo de su gentilidad $»^{36}$.

\footnotetext{
${ }^{33}$ Alonso Álvarez (2001), p. 181. 
DON QUIIJOTE EN EL PACÍFICO: LA CONSTRUCCIÓN DEL PROYECTO ESPAÑOL EN ASIA...

De ese modo, con la imposición de las reducciones, obligando a los indígenas a vivir en doctrinas y la reposición en ellas de la autoridad prehispánica, aunque bajo la supervisión del alcalde mayor español, se regularizó a partir de los años 90 el cobro del tributo y, con ello, pudo consolidarse el objetivo y la presencia española en las islas.

En el Cuadro 2, que reproduce el destino del gasto público, podemos observar cómo éste se dirigía ya a conformar una primitiva administración colonial -salarios ordinarios, pagos a oficiales reales, gastos de justicia y penas de cámara, factoría y gastos de tributos, el 83,21 por cien en la muestra analizada-, a transferir bienes y servicios para la continuidad de la conquista -pagas extraordinarias y gente de mar, el 9,91 por cien- y a suministrar recursos a los doctrineros regulares que ponían en práctica la política de concentración de población -ministros de doctrina, el 6,87 por cien.

\section{CUADRO 2}

GASTOS DE LA HACIENDA FILIPINA EN 1584 Y 1588 (EN PESOS DE A 8 REALES)

\begin{tabular}{|l|r|r|r|r|}
\hline & Año 1584 & Año 1588 & Totales & Porcentajes \\
\hline Salarios ordinarios & 16.544 & 30.552 & 47.096 & 47,71 \\
\hline Oficiales reales & 4.687 & - & 4.687 & 4,75 \\
\hline Gastos de justicia & - & 1.317 & 1.317 & 1,33 \\
\hline Penas de cámara & - & 946 & 946 & 1,00 \\
\hline Factoría & 9.000 & 17.532 & 26.532 & 26,90 \\
\hline Gastos tributos & 1.500 & - & 1.500 & 1,52 \\
\hline Pagas extraordinarias & - & 5.785 & 5.785 & 5,86 \\
\hline Gentes de mar & 4.000 & - & 4.000 & 4,05 \\
\hline Ministros de doctrina & 3.000 & 3.784 & 6.784 & 6,87 \\
\hline Subtotales & $\mathbf{3 8 . 7 3 1}$ & $\mathbf{5 9 . 9 1 6}$ & $\mathbf{9 8 . 6 4 7}$ & $\mathbf{1 0 0 , 0 0}$ \\
\hline
\end{tabular}

Fuentes: AGI, Contaduría, leg. 1200

\section{UN ATRACTIVO PARA LOS COLONOS HISPANO-MEXICANOS}

Conocidos ya el proyecto español en el Pacífico y los recursos con que los españoles contaban para sostenerlo, nos queda ahora por examinar la siguiente parte del ensayo, es decir, qué atractivo generaron para estimular el establecimiento 
en las Islas de colonos europeos y americanos que asegurasen su reproducción y continuidad.

Inicialmente, Manila era un centro en el que convergían los intereses de los colonos españoles, mexicanos y peruanos, pero también de los portugueses de Macao en el contexto de la unión de las dos coronas ibéricas. El atractivo que había estimulado el poblamiento de la capital de las Islas era el muy temprano comercio que se había establecido hacia Nueva España y el Perú, pero que había seducido todavía a muy pocos negociantes. Era aún una actividad reducida, ocasional y sin reglamentación alguna. De Manila salían productos de todo tipo, tanto de la tierra -generados por una agricultura cada vez más intensiva y una industria doméstica de crecientes rendimientos- como chinos e indostánicos, y a cambio acudía en abundancia a las Islas, y a todo el ámbito pacífico, la plata mexicana y peruana.

En el conjunto de las islas no se había producido -ni fue practicable hasta bien entrado el siglo xIX- una ocupación real del territorio, sino que se poblaban con hispano-mexicanos tan sólo determinados enclaves estratégicos, como la capital y Cebú. Sin embargo estos enclaves resultaban continuamente amenazados, en especial el de Manila. Existía un amplio espectro de enemigos exteriores -el sur islamizado, los competidores europeos-, pero sobre todo destacaba el peligro interior procedente de los campesinos de Luzón que no aceptaron sin más el dominio español, como demostraron las interminables revueltas contemporáneas en Zambales, Pampanga y Cagayán, que habitaban tres de las etnias más belicosas. Manila, la entonces modesta capital de un más deseado que real Imperio asiático, era tan sólo una ciudad de casas de madera y cubiertas de nipa, protegida únicamente por el río Passig, las ciénagas contiguas y el mar, con uno de sus costados indefenso. Pero aun la protección de la marina no era más que una precaria estacada, fácilmente franqueable, y una endeble fortaleza de tierra ${ }^{37}$. Lo inexplicable era más bien que la capital no hubiese sucumbido a los intentos de asedio a los que estuvo sometida durante los años precedentes ${ }^{38}$.

Esta situación de indefensión fue ampliamente expuesta por el jesuita Alonso Sánchez, comisionado por los vecinos de Manila, al Consejo de Indias en 1587. En la Instrucción reservada de 1589 que el propio monarca entregó a Dasmariñas

\footnotetext{
${ }^{37}$ En 1590 aún se mantenía operativa la pequeña empalizada de madera levantada por Legazpi, sólo muy ligeramente mejorada con un pequeño fuerte terrero construido por el gobernador Francisco de Sande en 1576. Véase Morga (1997) [1609], pp. 27 y 49. Sobre la ausencia de murallas, ironizaba el gobernador Dasmariñas en 1590 en su correspondencia a Felipe II: "Que no parece que se ha estado aquí sino como huéspedes, sin atender a más que no ver la hora de salir» (AGI, Filipinas, 18B, R.1, N.2).

${ }^{38}$ Especial mención merecen el asalto del pirata chino Limahon y la sublevación de los naturales de Manila durante el mandato del gobernador Guido de Lavezaris, que estuvieron a punto de liquidar la presencia española tras la muerte de Legazpi. Véase San Agustín (1975) [1698], p. 401.
} 
DON QUIIJOTE EN EL PACÍFICO: LA CONSTRUCCIÓN DEL PROYECTO ESPAÑOL EN ASIA...

-y que marcó un punto de inflexión en los objetivos de la Corona- aparece reflejada esta preocupación, instándose a las autoridades a levantar una muralla de piedra en torno a la ciudad, a edificar una fortaleza, a construir galeras para la vigilancia de las costas y a crear un campo con militares de soldada, porque hasta entonces subsistían del pillaje ${ }^{39}$.

La solución al problema de la precariedad de la protección vino por la vía del aumento del ingreso fiscal. El tributo indígena resultaba ya insuficiente para satisfacer los costes de defensa, por su tendencia a disminuir conforme avanzaba la conquista, lo que en principio puede parecer una contradicción. Pero la razón de esta caída del ingreso conforme aumentaban los tributos estaba en que en gran parte fueron cedidos por la Corona a militares que se habían destacado en la conquista, conformando lo que conocemos con el nombre de encomiendas, que no eran exactamente cesiones de tierras sino de tributos ${ }^{40}$. Las primeras medidas fiscales dirigidas a reclamar una mayor financiación de la defensa fueron excepcionales, implicándose en el gasto a encomenderos, cargadores y vecinos de Manila, lo que motivó algunas protestas ${ }^{41}$. Por esta razón acabó por aplicarse literalmente la Instrucción reservada que traía el Gobernador Dasmariñas, repercutiéndose el incremento del gasto sobre los tributos recaudados entre los campesinos indígenas. De esta manera, el peso de ocho reales que pagaba la familia campesina se amplió a diez, es decir, experimentó una subida de un 25 por cien por tributo, diferencia a la que se dio el nombre de situado real -que ingresaba la Hacienda y no los encomenderos- y que como tal aparece reflejado en las cuentas reales ${ }^{42}$.

El alza que experimentó la recaudación se aprecia bien en las cifras de las Cajas reales de Manila. Examinemos en primer lugar el Cuadro 3, que corresponde a los ingresos y gastos de 1588 y refleja la situación fiscal anterior a la subida del tributo. Aquí, el epígrafe que proporciona mayores ingresos a la Hacienda es el del tributo indígena -concepto que ahora no recoge todos los tributos, sino tan sólo los procedentes de las encomiendas que estaban en poder de la Corona-, que asciende a más de 30.000 pesos, muy por encima del impuesto sobre el tráfico marítimo -algo más de 18.000. El conjunto del cargo es muy moderado y no alcanza los 60.000, por lo que las posibilidades del gasto en defensa (factoría) resultaban todavía limitadas.

El Cuadro 4 reproduce la situación tributaria del primer año -en realidad, fueron tan solo unos meses- de la administración de Dasmariñas, en donde la aplica-

\footnotetext{
${ }^{39}$ AGI, Filipinas, 339, L.1. Ff. 365V-389R.

${ }^{40}$ La encomienda filipina pertenecía al tipo de encomienda nueva, la que se estableció en México tras la tragedia demográfica que supuso la primitiva encomienda antillana, que comportaba el reparto de trabajo indígena. Sobre la encomienda filipina, véase Hidalgo Nuchera (1995a).

${ }^{41}$ AGI, Filipinas, 18B, R.2, N.11.

42 Sobre la cuestión del situado mexicano, véase el trabajo de Bauzón (1981). También, Alonso Álvarez (2005b).
} 


\section{CUADRO 3}

INGRESOS Y GASTOS DE LAS CAJAS DE MANILA, 1588 (EN PESOS DE A 8 REALES)

\begin{tabular}{|l|r|l|r|}
\hline \multicolumn{1}{|c|}{ Cargo } & Pesos & Data & Pesos \\
\hline Tributos & 30.404 & Salarios & 30.552 \\
\hline Diezmos del oro & 3.909 & Ministros de doctrina & 3.784 \\
\hline Derechos de almojarifazgo & 18.174 & Factoría & 17.532 \\
\hline Cosas extraordinarias & 4.352 & Extraordinario & 5.785 \\
\hline Penas de cámara & 1.884 & Penas de cámara & 946 \\
\hline Justicia y estrados & 1.274 & Justicia y estrados & 1.317 \\
\hline Total cargo & $\mathbf{5 9 . 9 9 7}$ & Total data & $\mathbf{5 9 . 9 1 8}$ \\
\hline
\end{tabular}

Fuente: AGI, Contaduría, leg. 1200, fols. 1193 y 1204v. Elaboración propia

\section{CUADRO 4}

INGRESOS Y GASTOS DE LAS CAJAS DE MANILA, 1590 (EN PESOS DE A 8 REALES)

\begin{tabular}{|l|r|l|r|}
\hline \multicolumn{1}{|c|}{ Cargo } & Pesos & \multicolumn{1}{c|}{ Data } & Pesos \\
\hline Tributos & 26.364 & Salarios ordinarios & 27.220 \\
\hline Diezmos del oro & 3.732 & Doctrinas & 4.222 \\
\hline Derechos de almojarifazgo & 9.055 & Factoría & 19.892 \\
\hline Cosas extraordinarias & 25.893 & Pagas extraordinarias & 12.583 \\
\hline Condenaciones a penasde cámara & 1.920 & Penas de cámara & 474 \\
\hline Aplicados a gastos de justicia & 1.994 & Gastos de justicia & 1.116 \\
\hline Total cargo & $\mathbf{6 8 . 9 5 8}$ & Total data & $\mathbf{6 5 . 5 0 7}$ \\
\hline
\end{tabular}

Fuente: AGI, Contaduría, leg. 1200, fols. 1272-1305. Elaboración propia

ción del incremento del tributo -los dos reales del situado- aún no resultaba efectiva. Pero es el año de los nuevos ingresos para financiar las murallas, lo que refleja el epígrafe contable de cosas extraordinarias. Obsérvese cómo desciende la recaudación por tributo indígena en algo más del 13 por cien -de 30.404 a 26.364 pesos-, nada extraño cuando la Corona había renunciado a encomiendas que 
DON QUIIJOTE EN EL PACÍFICO: LA CONSTRUCCIÓN DEL PROYECTO ESPAÑOL EN ASIA...

entregaba a particulares destacados en la conquista y, sobre todo, por la reducción del número de contribuyentes derivada de la revuelta de los zambales y la pacificación del Cagayán. Descienden también -a la mitad- los ingresos en concepto almojarifazgo, debido al intento de Dasmariñas por reducir el tamaño del comercio con China para impedir extracciones de plata. Aumenta, sin embargo, la recaudación extraordinaria a más de 25 mil pesos y que permite el crecimiento del ingreso total -de 59.997 a 68.958, casi un 15 por cien-, lo que aseguró por tanto una mayor dedicación al gasto en defensa. Este gasto, que asciende a 19.892 pesos, es el que recoge el epígrafe de factoría.

El Cuadro 5 refleja una situación fiscal en la que se ha repercutido ya el incremento del tributo. El situado real aparece por primera vez en las cifras de la Hacienda, rebasando los 11 mil pesos. Prosigue no obstante la cobranza del impuesto extraordinario entre los españoles -que baja ligeramente en más de 10 mil pesos, algo que se compensa con el tres por ciento sobre el tráfico marítimo ante la protesta airada de cargadores y encomenderos. La nueva caída del tributo indígena obedece a las mismas causas analizadas para el ejercicio anterior. Sin embargo en el conjunto resultante crece la recaudación general respecto al año anterior en un 36 por cien, y en un 57 respecto a 1588. Ello permitió destinar más de 15.000 pesos a gentes de guerra y casi 13.000 a factoría, componiendo en total los gastos de defensa una cifra que sobrepasa los 28.000 pesos.

\section{CUADRO 5}

INGRESOS Y GASTOS DE LAS CAJAS DE MANILA, 1591 (EN PESOS DE A 8 REALES)

\begin{tabular}{|c|c|c|c|}
\hline Cargo & Pesos & Data & Pesos \\
\hline Tributos & 25.297 & Salarios ordinarios & 28.760 \\
\hline Diezmos del oro & 3.604 & Gentes de guerra & 15.756 \\
\hline Derechos de almojarifazgo & 349 & Doctrinas & 3.232 \\
\hline Situados reales & 11.532 & Prebendados & 5.687 \\
\hline Tres por ciento & 32.311 & Factoría & 12.977 \\
\hline Diezmos eclesiásticos & 3.732 & Pagas extraordinarias & 14.012 \\
\hline Cosas extraordinarias & 15.160 & Penas de cámara & 347 \\
\hline Penas de cámara & 1.910 & Gastos de justicia & 128 \\
\hline Aplicados a gastos de justicia & 294 & & \\
\hline Aplicados a gastos de guerra & 93 & & \\
\hline Total cargo & 94.282 & Total data & 80.899 \\
\hline
\end{tabular}

Fuente: AGI, Contaduría, leg. 1202, fols. 132v-133. Elaboración propia 
En el cuadro 6, que refleja las cifras fiscales de 1592, se ven consolidadas las tendencias anteriores. En primer lugar, se aprecia una continuidad en el crecimiento del situado, aunque se mantenga solapado y agregado al almojarifazgo -que debió resultar bajo por la continuidad de la política de Dasmariñas respecto al comercio con China que desincentivó el comercio. Se observa además una recuperación en la recaudación por tributo indígena a causa de una mayor eficiencia en su cobro derivada de las pacificaciones realizadas en la isla de Luzón, la política de reducciones y la integración de la aristocracia indígena en el proyecto español. Por ello, el conjunto de la recaudación sobrepasó los 123.000 pesos, lo que supone un incremento del ingreso del 30,5 por cien respecto al año precedente y un 105 por cien en relación al punto de partida (1588). Todo ello permitiría un crecimiento del gasto en gentes de guerra y factoría que se sitúa en algo más de 46.000 pesos. En conjunto, el gasto en defensa que en 1588 se elevaba a algo más de 17.000 pesos subió en 1590 en un 13 por cien, un 63 en 1591 y un 164 en 1592.

Hasta ahora hemos visto confirmado el incremento del gasto en defensa que exigió un crecimiento del ingreso por la vía de un alza en el tributo a los campesinos o, si se prefiere, de la introducción del situado real. Esta subida fue realizada con gran cautela por parte del Consejo de Indias. La Instrucción reservada ordenaba a Dasmariñas la adopción de una estrategia de flexibilidad en la recaudación, de manera «que no se pudiere forzar a los indios a pagarlo en cosa señalada [producto] sino en dinero si lo tuvieren o quisieren dar, o en cualquier otra cosa de sus frutos o granjerías» ${ }^{43}$. La Instrucción facultaba abiertamente que los campesinos indígenas pudiesen decidir la forma de pago: en especie, como hasta entonces, hasta completar los diez reales, en dinero o en ambas modalidades. La posibilidad del pago en dinero -la menos gravosa para los tributantes, como veremos- se iba a convertir así en una modificación fundamental en la fiscalidad, cuyos efectos inducidos resultaron de especial relevancia en la evolución de la economía y eludieron las reservas del Consejo de Indias.

Podríamos interrogarnos por las razones de esta (digamos) inusual y graciosa asignación de la Corona. Resulta evidente que en el espíritu de la Instrucción planeaba un cierto temor a la generalización de las revueltas antifiscales. En aquellos momentos estaba comenzando el proceso de concentración de la población en doctrinas y de asimilación de la principalía indígena, no estaba en suma finalizada la conquista y muchos campesinos de Luzón mantenían en jaque a las tropas españolas enviadas para su represión. Ya he mencionado la rebelión de los zambales, pampangos y cagayanes, que guardaba relación con los abusos en el cobro de los impuestos por parte de los encomenderos. Por este motivo, el propio Gobernador había sido contrario a la subida de las cargas fiscales a los campesinos. Como telón de fondo, se ha de señalar que aún quedaban sin resolver algu-

${ }^{43}$ AGI, Filipinas, leg. 339, L.1, Ff. 365V-389. 
DON QUIIJOTE EN EL PACÍFICO: LA CONSTRUCCIÓN DEL PROYECTO ESPAÑOL EN ASIA...

\section{CUADRO 6}

INGRESOS Y GASTOS DE LAS CAJAS DE MANILA, 1592 (EN PESOS DE A 8 REALES)

\begin{tabular}{|l|r|l|r|}
\hline \multicolumn{1}{|c|}{ Cargo } & Pesos & \multicolumn{1}{c|}{ Data } & Pesos \\
\hline Tributos & 32.053 & Salarios ordinarios & 35.559 \\
\hline Diezmos del oro & 3.533 & Gente de guerra & 25.150 \\
\hline Situado y derechos de almojarifazgo & 60.535 & Doctrinas & 3.742 \\
\hline Diezmos eclesiásticos & 6.933 & Factoría & 21.214 \\
\hline Extraordinario & 17.559 & Prebendados & 2.142 \\
\hline Penas de cámara & 1.661 & Pagas extraordinarias & 17.500 \\
\hline Gastos de justicia & 563 & Penas de cámara & 60 \\
\hline Gastos de guerra & 244 & Gastos de guerra & 143 \\
\hline Total cargo & $\mathbf{1 2 3 . 0 8 1}$ & Total data & $\mathbf{1 0 5 . 5 1 0}$ \\
\hline
\end{tabular}

Fuente: AGI, Contaduría, leg. 1202, fols. 141v y 156v. Elaboración propia

nas de las cuestiones que, como la recaudación en las encomiendas sin doctrina -los encomenderos cobraban el tributo sin proporcionar la contraprestación religiosa que exigía la legislación de Indias-, había sólo planteado, pero no resuelto, el Sínodo de Manila de 1582. Por todo ello, no resulta extraña esta actitud cautelosa en las autoridades españolas respecto al cobro de tributos, dando facilidades a los campesinos para hacer más digerible la subida impositiva. En conjunto, esto significaba que éstos iban a adoptar como respuesta generalizada el pago en metálico. Para ellos resultaba sencillo reunir el peso más los dos reales del situado, una cantidad asumible por sus economías domésticas si consideramos que el pago en especie había llegado a sextuplicar la valoración del tributo. Era algo que podían realizar fácilmente a través de la venta de servicios a los españoles, desde el doméstico a los cortes de madera para construir embarcaciones. En este sentido es reveladora la información que Dasmariñas envía al Rey por la vía reservada:

«[Los campesinos indígenas] saben que cumplen [fiscalmente] dando su tributo en reales, los cuales sacan de cuatro plátanos que traen a vender a Manila o de un servicio de un mes [...], a los cuales se aplica más, porque como son amigos del ocio so color de ellos, andan vagamundos ociosos y en borracheras y otras ofensas de Dios y de la doctrina y au- 
sentes cincuenta y sesenta leguas y más de sus casas y mujeres e hijos por muchos meses y por ventura todo el año entero» ${ }^{44}$.

El pago del tributo en dinero era así lo que iba a alterar de manera significativa en el medio plazo el desarrollo de la economía indígena, en la medida en que desbarataba el mecanismo de distribución en el mercado, hasta el punto de poner en cuestión el modelo de control colonial. Existe una gran abundancia de evidencias de cómo esta oportunidad de que dispusieron los campesinos para atender sus obligaciones fiscales les llevó a un abandono de buena parte de sus actividades en la agricultura y en la industria doméstica. En la medida en que el antiguo tributo les había forzado al pago en especie, se habían visto coaccionados a trabajar más allá de la subsistencia, de manera que producían también para alcanzar el pago del tributo, colocando el excedente en los mercados de Manila y Nueva España a través de las bandalas o de la venta directa a los españoles y residentes chinos. Pero al desaparecer la obligación fiscal del pago en especie -y permitir por tanto el pago en dinero, de fácil obtención- dejó sin efecto el mecanismo coactivo sobre la actividad agraria, de manera que comenzaron a abandonar la ocupación rural, provocando en el medio plazo una gran escasez de bienes, algo que reflejan con abundancia los testimonios de la época ${ }^{45}$. Esta carestía de alimentos y manufacturas se tradujo en el corto plazo en una grave inflación -que había comenzado ya con la llegada de la plata novohispana-, como los propios contemporáneos alcanzaron a apreciar ${ }^{46}$.

${ }^{44}$ AGI, Patronato, 25, R.52.

${ }^{45} \mathrm{El}$ propio Dasmariñas señalaba en el mencionado documento que «así no atienden [los campesinos] al sembrar, criar ni beneficiar los dichos frutos y rescates. Por donde se vienen a perder. Lo cual no sería si el indio supiese que ha de pagar en especie, porque beneficiaría y sembraría para pagar su tributo y para vender también y aprovecharse codicioso de las ganancias que tendría en ello, porque no solo ganará con el encomendero, a quien lo da en tributo, pero vendiéndolo a otros personas ganará mucho más». AGI, Patronato, 25, R.52.

Y más adelante abundaba en lo mismo:

«Porque como el indio ve que cumple con diez reales, los que gana en un día en una grangería, después todo el año huelga y anda ocioso y vagabundo en borracheras [...] y con esto no siembran, ni crían, ni tejen, ni beneficia frutos de la tierra. Y así ya no se halla arroz, ni una mota de lompote de la tierra, que vale más que tres de la China, ni algodón, cera, oro ni otros rescates. Y se pierde el trato en lo de aquí, que de todo esto había y en muy baratos precios, cuando pagaban en especie y no a escoger». Ibídem.

Cursiva del autor. Los lompotes eran telas de algodón tejidas por las mujeres indígenas. Véase Rodríguez (1978), II, p. 358, y I, p. 531, así como Martínez de Zúñiga (1803), II, pp. 88 y 95. También se les llamaba gasas de Cebú.

${ }^{46}$ Según una carta de Dasmariñas al Rey, fechada en 20/06/93, «cuando los dichos indios pagaban en especie, la tierra estaba mantenida, [a]bastecida y asimismo abundante de esos dichos rescates [...]. Y ahora no solo se ha encarecido todo, pero no se halla, pues soliéndose dar trescientas y cuatrocientas gantas de arroz al tostón y ahora no se halla una por dos reales o tres, dábanse quince o veinte chinantas de algodón 
La red que los chinos -sangleyes en los textos de época- empezaron a extender en las actividades mercantiles y su creciente influencia en la carrera de Nueva España no resultaban novedosos a comienzos de la década de los 90. El gobernador Gómez Pérez Dasmariñas llevaba órdenes estrictas para aminorar este ascendiente, como reflejan los contenidos de su Instrucción reservada.

Se puede situar el punto de inflexión del poder de los sangleyes en la actividad exterior a fines de la década de los 80 , si nos guiamos por las referencias que aparecen años después en carta al Rey firmada por el gobernador don Francisco Tello de Guzmán (1596-1602). En una larga reflexión sobre el alcance del comercio con China durante los últimos años, constataba que había experimentado un alza relevante. Señalaba también que sus comienzos habían sido muy precarios -se había mantenido con sólo dos barcos-, pero, desde una fecha que él situaba en torno a 1589, arribaban ya más de 75 navíos del continente con sedas y mantelerías para remitir a Nueva España por un valor superior al millón de pesos ${ }^{47}$. La datación del gran cambio puede situarse así, según la fuente, al final del gobierno del Doctor don Santiago de Vera (1584-1590). Hasta entonces, como vimos, las evidencias revelaban que las exportaciones del archipiélago a México se nutrían en gran medida de productos filipinos, completados con mercancías chinas. Esto explica que sólo un año después Dasmariñas trajese órdenes precisas del Consejo de Indias para reducir la influencia de los chinos, que intentó contrarrestar con la introducción de un instrumento jurídico que los españoles conocían con el nombre de pancada ${ }^{48}$. Al obligar a los comerciantes sangleyes a vender al por mayor sus mercancías en el puerto -que en esto consistía la pancada-, recortaba los beneficios superiores que hubiese proporcionado a los mercaderes chinos una venta directa al mejor postor.

al tostón y ahora no se hallan ocho ni seis. El tae de oro que solía valer cinco pesos, vale ahora nueve y no se halla. Pues en muchas partes donde S.M. solía cobrar cuatrocientos y quinientos y más taes de oro no se han cobrado este año veinte. Un lompote, ni una manta, un medriñaque no se halla, porque no se hace». AGI, Patronato, 25, R.52.

La ganta era una medida de capacidad que equivalía a 8 chinantas, es decir, 3 litros. El tostón era una moneda de plata portuguesa, de uso generalizado en el Pacífico, equivalente a 4 reales mexicanos. El tae o tael era una referencia china para el calibrado del oro que contenían las monedas y equivalía a 0,03954 kg. Los medriñaques del Pacífico, escrito también mendriñaques, eran tejidos de abacá lisos. Los listados llevaban trama de algodón -Pastells (1926), t. I, p. 39-; según Chirino (2000) [c. 1610], p. 82, eran telas bastas; según Grau y Monfalcón (1866) [1637], p. 380, los medriñaques eran «telas fuertes de algodón, de que también se hacen medias».

${ }^{47}$ Morga (1997) [1609], p. 193.

48 «Real disposición para que de las islas Filipinas no se trate en la China» de 11 de enero de 1593, en AGI, Indiferente, 433, L.2, F.190V-191V. En la «Orden sobre la venta de géneros de China», de 11 de junio de 1594 señalaba el Rey que «las mercaderías que van y vienen de la China se vendan en montón a un precio por personas diputadas para ello, que es lo que llamáis la pancada». AGI, Filipinas, 339, L.2, F.64R-64V. 
El Gobierno trató por todos los medios de frenar esta influencia comercial de los sangleyes. Dasmariñas inició una investigación exhaustiva, a instancias del Consejo de Indias, sobre el alcance de la entrada en las Islas de los productos chinos, publicando una ordenanza en la que prohibía su consumo a los campesinos indígenas ${ }^{49}$. La argumentación esgrimida por el Gobernador era la siguiente: antes de la llegada de los españoles, los habitantes de las islas vestían tejidos que ellos mismos se confeccionaban, pese a recibir visitas esporádicas de los negociantes de Fujian, la provincia comercial del sur de China ${ }^{50}$. Sin embargo, con el establecimiento de los españoles se había difundido el consumo de sedas y ropas chinas entre los campesinos indígenas ${ }^{51}$. Según determinadas evidencias, se adquirían en cantidades significativas:

«Ha llegado a tanto exceso que no hay ningún año que los dichos naturales no compren ni gasten en sus vestidos sobre doscientas mil mantas de algodón y seda, que agora valen otros tantos miles de pesos» ${ }^{52}$.

Dasmariñas explicaba también cómo aquéllos podían adquirirlas: tanto a través de servicios a los españoles (polos), «como por otras muchas vías que hay». El resultado fue considerado preocupante para la economía de las Islas:

«Se sigue un gran daño a estas islas y de servicio a Su Majestad, y es que con la ropa que los chinos sacaban treinta mil pesos en dinero de estas islas, agora, por el desorden y exceso de los naturales sacan doscientos mil y éstos salen de los reinos de Su Majestad y se llevan a reino extraño» ${ }^{53}$.

La solución adoptada por el gobierno de Manila no fue otra que la de aplicar políticas prohibicionistas a la importación de tejidos chinos. Pero era poner puertas al campo: frente el encarecimiento de los productos de la agricultura e industria doméstica, los chinos distribuían mercancías muy baratas, al mantener unos costes de producción y de transporte muy bajos -y no resultar afectadas además por la inflación filipina-, lo que les permitía competir con ventaja ${ }^{54}$. Por estas razones acabaron por imponerse en las transacciones con la Nueva España.

${ }^{49}$ AGI, Patronato, 25, R.41.

${ }^{50}$ «Cuando vinieron los españoles al descubrimiento de estas islas, los naturales de ellas no vestían otra ropa sino la de la tierra, cogiendo algodón y haciendo mantas para su vestir». AGI, Patronato, leg. 25.

${ }_{51}$ «Después que los españoles poblaron y los chinos comenzaron a engrosar la contratación con ellos, trayendo muchos navíos de ropa a estas islas, los naturales comenzaron a vestirse de la dicha ropa de China, dejando la suya que antes usaban». Ibidem.

${ }^{52}$ Ibídem.

${ }^{53}$ Ibídem.

${ }^{54}$ El propio Consejo de Indias señalaba en 1587: «y ellos [los sangleyes] han vendido lo que traen tan barato que hacen pensar que lo hallan en su tierra de balde». Morga (1997) [1609], p. 77. Un año después, el Obispo Salazar recordaba en España al Consejo que «los mercaderes chinos acudieron hogaño tantos a esta ciudad, que vinieron las mercaderías a valer de balde». Morga (1997) [1609], p. 79. 
Entre los hispano-mexicanos, los perdedores de esta gran transformación fueron los encomenderos cuyo ingreso dependía en exclusiva del tributo -mientras que los ganadores fueron los frailes regulares, en especial los dominicos, que apoyaron la mayor presencia de los sangleyes en el comercio del galeón ${ }^{55}$. Los recursos que les proporcionaban sus haciendas-encomiendas que, bajo tributo en especie, eran canalizados hacia los mercados de Manila y Nueva España, resultaban ahora mucho más costosos a comienzos de los años noventa y encontraban una difícil salida en la carrera de México. Estas complicaciones explican también su actitud beligerante en la cuestión de las encomiendas sin doctrina y en su relación con los campesinos adscritos, que se cargó de especial brutalidad.

Los encomenderos, agrupados en torno al gobernador Dasmariñas, intentaron presionar a la Corona. Eran conscientes de que la clave de su pérdida de influencia guardaba relación con las modificaciones introducidas en la recaudación tributaria, por lo que reclamaron un retorno de la vieja normativa fiscal. Pero la lentitud en la correspondencia postal acabó por resultar determinante en un territorio periférico que distaba más de 10.000 leguas y a muchos meses de navegación de los centros de decisión del Imperio. El Consejo de Indias pidió en agosto de 1592 un «Informe sobre escasez de frutos, ganado y ropas» pero, ante la dilación de la resolución definitiva, el Gobernador reunió y presidió en marzo de 1593 una Junta constituida por «cabildo, justicia y regimiento de esta ciudad de Manila y todos los teólogos de ella y prebendados de la catedral», en suma, el conjunto de estamentos que conformaban los intereses hispano-mexicanos ${ }^{56}$. En ella se pusieron de manifiesto los problemas que la orden de modificación de la normativa tributaria había producido en la colonia, y no solo en los intereses de los encomenderos:

«De la ejecución de la dicha orden se echaron luego de ver que resultaban muchos inconvenientes, como era que viendo el indio que con reales cumplía, no sembraba ni criaba, ni beneficiaba los demás rescates de la tierra, de que procedía general hambre y carestía en todas las cosas» ${ }^{57}$.

De aquí derivaría que «el trato de las cosas de esta tierra se perderá, en el cual se funda el sustentarse aquí los españoles y las iglesias y esta nueva planta del Evangelio», según expresión de la autoridad colonial ${ }^{58}$. Se argumentaba, así,

${ }^{55}$ En general, la consolidación del comercio del galeón favoreció los intereses de los eclesiásticos, en especial en lo referente a la financiación del tráfico colonial. En este sentido, en 1594 se creó la más importante de las Obras Pías, la Hermandad de la Misericordia, entre cuyas funciones estaba la de dar a riesgo marítimo -seguro y financiación- las mercancías que los hispano-mexicanos asentados en Manila conducían a América.

${ }^{56}$ AGI Filipinas, 340, L.3, Ff. 116R-116V.

${ }^{57}$ Las referencias a las discusiones de la Junta mencionada proceden todas de AGI, Patronato, 25, R.46.

${ }^{58}$ Ibídem. 
con las evidencias que resultaban más sensibles a la estrategia real: la modificación tributaria desincentivaba, en opinión de la Junta, la precaria permanencia española en la colonia asiática, al afectar a aquella actividad que empezaba a retener una pequeña población de colonos en las islas, el comercio del galeón: «Pues es cosa clara que si falta lo de China, español que a esta tierra viene no halla en ella algún aprovechamiento y mejora se irá de ella o no vendrán más y esto se acabará» ${ }^{59}$.

En resumen, el pago en dinero derivado del cambio tributario desincentivaba la agricultura e industria domésticas, originando una gran escasez de productos, con lo que desaparecería el comercio de intermediación entre el Archipiélago y la Nueva España. Y por ello, la retirada de los efectos filipinos en la feria de Acapulco implicaba un aumento significativo en el número de los procedentes de China, lo que suponía una mayor extracción de plata y una caída de la rentabilidad del galeón, al punto de desincentivar la presencia española.

Las decisiones tomadas en la Junta de 1593 tardaron en llegar al Consejo de Indias. A ello hemos de añadir la labor de oposición que ejercitó una parte de la Iglesia, en especial la más vinculada al Obispo de Manila, el dominico Salazar, ante el propio Consejo. Salazar llegó a desplazarse personalmente a España para explicar en directo al Monarca las razones que le enfrentaban con el Gobernador y los encomenderos. Esto obligó a la Corona a tomarse un tiempo adicional de consulta y reflexión antes de comunicar su dictamen, lo que debilitó aún más la posición de los encomenderos, pese a que Dasmariñas publicó un bando en el que se ordenaba una vuelta a la antigua situación en tanto no llegaban las instrucciones del Consejo $^{60}$. Los años de moratoria resultaron fundamentales para que los efectos perversos inducidos por el cambio tributario -pérdida de peso relativo de la agricultura, inflación y, sobre todo, sustitución de los productos filipinos por mercancías chinas en la carrera de México- mantuvieran una relevancia decisiva para el futuro de la colonia.

Cuando en 1593 promulgaron el Reglamento de la carrera de la Nueva España, las autoridades imperiales parecían tener ya bien claro un futuro para la conservación de las Islas bajo administración española ${ }^{61}$. La Corona sacrificó los intereses de los encomenderos y aceptó la nueva realidad por la vía de los hechos consumados: el comercio de China con la Nueva España a través de Manila. Se apartó,

\footnotetext{
${ }^{59}$ Ibídem.

${ }^{60}$ Dirigido a los alcaldes mayores y corregidores, con fecha de 10 de junio de 1593 . En él se ordenaba «a los dichos justicias y a cada uno de vos que de aquí en adelante los naturales que están en vuestras jurisdicciones den y paguen a sus encomenderos y a Su Majestad el tributo que están obligados en especie a los precios que valieren al tiempo que pagaren los dichos tributos, según es como lo daban y pagaban antes que se publicara la nueva orden y cédula de Su Majestad». AGI, Patronato, 25, R. 46.

${ }^{61}$ AGI, Indiferente, 433, L. 2, Ff. 190V-191V.
} 
DON QUIIJOTE EN EL PACÍFICO: LA CONSTRUCCIÓN DEL PROYECTO ESPAÑOL EN ASIA...

también, a portugueses y peruanos del comercio del galeón, que derivó en monopolio hispano-mexicano. Se acabó por legalizar, además, la importación de productos chinos, que mantuvo el modelo que aseguraba la conservación de las Islas sin excesivos costes para la Corona ${ }^{62}$. La prematura muerte del gobernador Dasmariñas en 1593 privó a los encomenderos de su mayor aliado.

Con todo, el Consejo de Indias intentó buscar una solución de compromiso que, sin dañar la nueva constelación de intereses que se había conformado en torno a la negociación de China, no recortase excesivamente el poder de los encomenderos, dado que la precariedad que llegaron a alcanzar las encomiendas podía desincentivar a los militares españoles. Pero fue ya una decisión tardía (1595), que se conoció además durante el mandato interino del gobernador Luis Pérez Dasmariñas $^{63}$. En ella se permitía el pago del tributo en especie y en dinero, a partes iguales. Cuando llegó a aplicarse en toda su amplitud, la tendencia al crecimiento de los precios de los productos autóctonos se había consolidado y las diferencias respecto a los efectos chinos se habían agrandado, mientras que, por otra parte, los bajos precios de estos últimos en los mercados mexicano y peruano había conectado con las preferencias de los consumidores de menores ingresos.

En esta confrontación de intereses entre colonos hispano-mexicanos, los grandes perdedores habían sido, como vimos, los militares tenedores de encomiendas. No obstante, su pérdida de influencia resultó tan solo parcial, porque uno tras otro acabaron por aceptar la nueva realidad, convirtiéndose en cargadores en la carrera de la Nueva España. Sin embargo, la posición de las haciendas-encomiendas en el conjunto resultante devendría en un elemento cuasi residual para la economía filipina. Las haciendas resultaban ya inviables como unidades de producción -ajustando la oferta de alimentos al menor tamaño del mercado-, su decadencia se manifestó a lo largo del siglo xviI y quedó confirmada a finales del Seiscientos cuando desaparecieron en su inmensa mayoría -al fenecer sus voces-, reintegrados sus tributos a la Corona en el nuevo diseño de administración provincial $^{64}$.

Quedaba, sin embargo por resolver una cuestión que afectaba a la estabilidad de la colonia. Desde comienzos del siglo Xvir un nuevo peligro exterior amenazaba la conservación de las Islas bajo soberanía española. Se trataba de la respuesta de los holandeses a lo que consideraban una provocación de la política imperial,

\footnotetext{
${ }^{62}$ La actitud de la Corona hacia los chinos cambió desde entonces. En un documento de 1594 el Rey recomendaba a D. Luis Pérez Dasmariñas, gobernador interino, «que los dichos sangleyes chinos no reciban agravio ni se les dé ocasión a que dejen de venir a sus contrataciones, guardando cerca de esto lo contenido en la cédula de once de enero del año pasado». AGI, Filipinas, 339, L. 2, Ff. 64R-64V.

${ }^{63}$ Fue confirmada durante el mandato del gobernador Pedro Bravo de Acuña en 1604. Véanse Hidalgo Nuchera (1995a), pp. 174 y 191, y Alonso Álvarez (1999), p. 95.

${ }^{64}$ Alonso Álvarez (2003b).
} 
en el contexto de la unión de las dos coronas ibéricas, y que afectaba a los rendimientos de la Verenidge Oost Indische Compagnie (VOC). Los frecuentes ataques a los intereses españoles en Asia (Cuadro 7) se extendieron a lo largo del primer cuarto de siglo -y se continuaron en el segundo hasta la Paz de Westfaliaal punto de poner en jaque la continuidad de la colonia. ¿Cómo financió la Administración española la defensa frente a estas agresiones? Estaba claro que todo aumento de la fiscalidad sobre el tributo y el comercio (almojarifazgo) resultaba inviable dado el equilibrio fiscal existente. Hasta entonces la Hacienda filipina se había autofinanciado, con costes muy bajos para la Administración imperial. Sin embargo, la guerra hispano-holandesa hizo necesaria la financiación exterior, procedente del virreinato mexicano, en forma de situado.

\section{CUADRO 7}

\section{PRINCIPALES INTERVENCIONES DE LAARMADA HOLANDESA EN FILIPINAS ENTRE 1600 Y 1624}

\begin{tabular}{|l|l|}
\hline Año & \multicolumn{1}{|c|}{ Acciones } \\
\hline 1600 & Persecución del galeón. Captura de diversos barcos mercantes \\
\hline 1610 & Batalla contra flota española en Mariveles \\
\hline 1614 & Bloqueo de Manila y paralización del comercio \\
\hline 1616 & Bombardeo de Iloilo. Cerco de Manila y resistencia ciudadana \\
\hline 1617 & Batalla contra la Armada española en Zambales \\
\hline 1619 & Merodeos y pillajes por las Visayas \\
\hline 1620 & Ataque al galeón «San Nicolás» \\
\hline $1621-22$ & $\begin{array}{l}\text { Bloqueo de año y medio de Manila. Ataques a juncos chinos y } \\
\text { paralización del comercio }\end{array}$ \\
\hline 1624 & $\begin{array}{l}\text { Bloqueo de Manila. Batalla contra la flota española. Ataque al } \\
\text { galeón }\end{array}$ \\
\hline
\end{tabular}

Elaboración propia

Desde la perspectiva de la contabilidad imperial, situado era toda transferencia ejecutada desde una caja con superávit a otra con déficit fiscal en el conjunto tributario del Imperio español, supuesta la unidad de cajas. Mantenía, además, aunque no siempre, un componente de ayuda militar. De ahí que los situados más conocidos abarcasen las áreas marginales de América y Asia: Filipinas, Floridas, 
Chile e islas del Caribe ${ }^{65}$. Con todo, la finalidad de los primeros situados hay que relacionarla con un concepto algo más genérico que el de la defensa del Imperio, como es el de financiación de sus costes de reproducción o mantenimiento. Entre ellos, los costes de defensa eran muy altos, pero también podían serlo los de administración e incluso los de evangelización del territorio. Por ello, nos encontramos con ayudas destinadas a financiar al pago de tropas e incluso fortalezas y presidios, pero también para la retribución de los estipendios o determinadas necesidades de los religiosos doctrineros, para los sueldos y salarios de los capitanes generales y funcionarios de la Audiencia y la Hacienda o, como en el caso de la Habana, para la gestión del monopolio del tabaco ${ }^{66}$. Con todo, en las Filipinas el situado se destinó básicamente a financiar los costes de defensa que entonces alcanzaron una subida espectacular con el inicio de las hostilidades con los holandeses, como puede verse en el Gráfico 1.

Como territorio de frontera frente al avance del Islam en Asia, pero también frente a una población indígena hostil y a unos competidores holandeses, británicos y, en algún momento, portugueses, el archipiélago destinó en los dos largos siglos que transcurrieron entre fines del XVI y los primeros años del XIX una partida elevada de sus recursos a defensa. Esta observación es especialmente relevante en lo referente al primer cuarto del siglo xvII, como se aprecia en el gráfico.

\section{GRÁFICO 1}

EVOLUCIÓN DEL GASTO MILITAR EN LAS CAJAS DE MANILA, 1580-1660

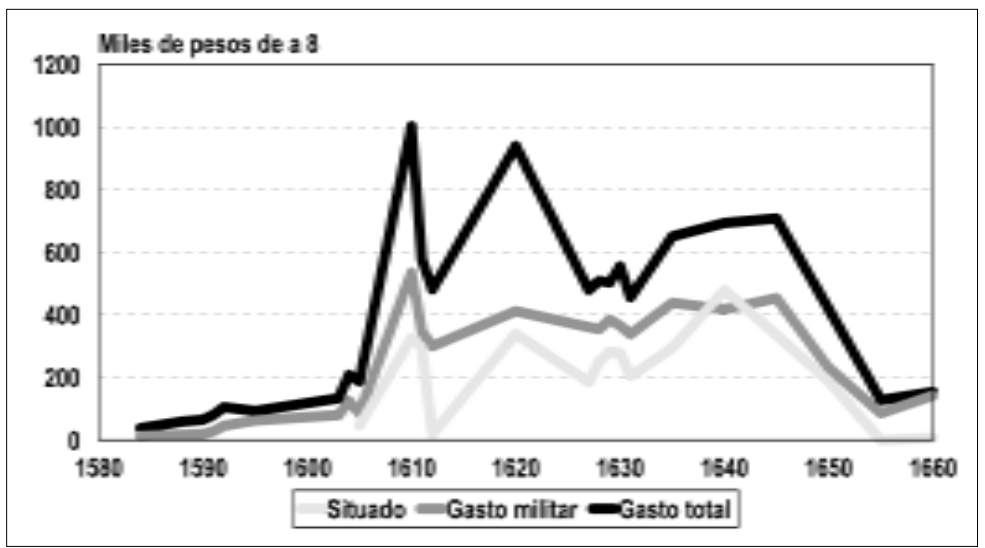

Fuente: AGI, Contaduría, legs. 1195-1291 y Filipinas, legs. 858-871. Elaboración propia.

\footnotetext{
${ }^{65}$ Todas las referencias al situado, en Alonso Álvarez (2005b).

${ }^{66}$ Marichal y Souto (1992), pp. 33-34.
} 
Sin embargo, si nosotros analizamos las partidas tributarias de los primeros cuarenta años de la ocupación española (1565-1604), observamos que no existe ese déficit fiscal que justificaba las transferencias de dinero y de recursos. El análisis de la contabilidad de las cajas filipinas para los años en que la documentación es más inteligible nos muestra que aquéllas apenas generaban balances negativos, salvo para los años 1584 y 1604. Dicho de otro modo, hasta el final de la conquista -que podemos establecer en 1604, el año que comenzaron las agresiones de los holandeses ${ }^{67}$ - no se produjo un déficit fiscal. Y la razón era que los ingresos recaudados en las Islas -especialmente el tributo indígena y su situado real, los derechos de almojarifazgo y los extraordinarios- resultaban suficientes para financiar el gasto. Sería la guerra con Holanda la que cargase de gasto extraordinario a la Hacienda pública y exigiese el socorro procedente de la Nueva España. Pero, como vimos, se trataba de un gasto necesario, cuya ejecución hizo descender la inversión en defensa en América y protegió de manera más eficiente la producción de plata. He aquí, pues, la utilidad de las Islas Filipinas en el contexto del Imperio.

\section{CONCLUSIÓN}

Hemos visto cómo la presencia imperial en las Islas Filipinas, tras avances y retrocesos, acabó conformando un territorio destinado a la protección de los intereses españoles en las Indias Occidentales. Los medios financieros para sostener una Administración española procedieron básicamente del esfuerzo fiscal de los campesinos indígenas -a través del complejo tributario- y, en menor medida, de las actividades comerciales de los hispano-mexicanos, pero, en todo caso, constituía una financiación de procedencia interna y sin excesivos costes para el conjunto del Imperio. El instrumento para atraer a los colonos -fracasado el sistema de encomiendas- acabó por conformar un comercio de intermediación entre Asia y América y que dio cohesión a la colonia. Hasta este momento, que hemos de situar a comienzos del siglo XVII, la implicación de la Corona en Asia constituyó una política que podemos calificar de escasamente utópica, que armonizaba más

\footnotetext{
${ }^{67}$ Hablo de conquista en términos convencionales. Es de sobra conocido cómo los hispanomexicanos ocuparon tan solo una mínima parte del territorio, el área de influencia de las dos ciudades europeas, Manila y Cebú, lo que les permitió sostener sin grandes costes el comercio del galeón. El resto de las Islas fue guarnecido con dotaciones militares mínimas, situadas en las cabeceras de provincia, para asegurar el cobro del tributo y la prédica evangélica. La isla de Mindanao, el archipiélago de Joló y en general las uplands, donde se practicaba una agricultura de slash-and-burn muy autosuficiente, permanecieron impenetrables a la influencia europea y su auténtica colonización no comenzó hasta el siglo xix y se continuó en el xx con la ocupación americana.
} 
DON QUIIJOTE EN EL PACÍFICO: LA CONSTRUCCIÓN DEL PROYECTO ESPAÑOL EN ASIA...

con lo que solemos identificar con la figura de Sancho en oposición a la de Don Quijote. ¿Cuál fue, pues, la intervención del noble caballero en el Pacífico hispano que da título a esta reflexión? El cambio de estrategia tributaria en el conflicto que plantearon los holandeses hacia 1606. Está claro que la lanza de Don Quijote se puso de nuevo del lado de los débiles, de los que no disponían ahora de recursos suficientes para defenderse, una lanza-situado procedente de la Nueva España. Así toman un nuevo sentido las palabras con que comenzaba este trabajo, extraídas del historiador francés Chaunu: «les Philippines ont coûté à l'Espagne, à la belle époque, 10 à 15\% environ de ce que pouvaient lui rapporter les Indes».

\section{FUENTES}

Archivo General de Indias, Sevilla (AGI))

\section{BIBLIOGRAFÍA}

Academia [Española] de la Historia (1886): Colección de Documentos Inéditos relativos al descubrimiento, conquista y organización de las antiguas posesiones españolas de Ultramar. Madrid, vol. 1.

Alonso Álvarez, L. (1999): «El alimento de Manila. Un acercamiento a los niveles de mercantilización de la economía filipina durante la época colonial temprana», en A. Carreras et al., La industrialización y el desarrollo económico de España. Barcelona: Universidad de Barcelona, vol. I, pp. 95-106.

- (2000): «Repartimientos y economía en las islas Filipinas bajo dominio español, 15651815», en Margarita Menegus (coord.), El repartimiento forzoso de mercancías en México, Perú y Filipinas, siglos XVI-XVIII. México DF: Instituto Mora y UNAM, 170216.

- (2001): «La inviabilidad de la hacienda asiática. Coacción y mercado en la formación del modelo colonial en las islas Filipinas, 1565-1595», en D. Elizalde, J. M. Fradera y L. Alonso Álvarez (eds.), Construcción de imperios y naciones en el Pacífico (siglos XVIXX). Madrid: CSIC, vol I, pp. 181-206.

- (2003a): «Financing the Empire. The nature of Spanish taxation system in the Philippine Islands, 1565-1804», Philippine Studies 51, no. 1, pp. 63-95.

- (2003b): «»¿Qué nos queréis, castillas?» El tributo indígena en las islas Filipinas entre los siglos xvi y xviii». Jahrbuch für Geschichte Lateinamerikas 40, pp. 13-42.

- (2005a): «Los señores del barangay. La principalía indígena en las islas Filipinas, 15651789: viejas evidencias y nuevas hipótesis», en Margarita Menegus, El cacicazgo en la Nueva España y Filipinas. México DF: CESU-UNAM y Plaza y Valdés Editores, pp. 355-406.

- (2005b): «La ayuda mexicana en el Pacífico: socorros y situados en Filipinas, 15651816». Ponencia presentada al Congreso El situado en el Imperio colonial español. Cartagena de Indias (Colombia), Agosto de 2003 (en prensa). 
Álvarez de Abreu, A. (1977) [1736]: Extracto historial del comercio entre China, Filipinas y Nueva España. México DF: Instituto Mexicano de Comercio Exterior, tomo 2.

Bauzon, L. E. (1981): Deficit Government. Mexico and the Philippine Situado, 1606-1804. Tokio: The Centre for East Asian Cultural Studies.

Benavides, M. DE (c. 1595): «Ynstruccion para el govierno de las Filipinas y de como los an de regir y governar aquella gente», en L. Hanke (1943), Cuerpo de documentos del siglo XVI sobre los derechos de España en las Indias y las Filipinas. México DF: Fondo de Cultura Económica, pp. 202-203.

Blair, E. H. y RoberTson, J. A. (1903-1909): The Philippine Islands, 1493-1898. Cleveland: Arthur H. Clark, tomo 27.

Chaunu, P. (1960): Les Philippines et le Pacifique des Ibériques (XVI $e^{e}$ XVII ${ }^{e}$, XVIII ${ }^{e}$ siècles). Introduction Méthodologique et Indices d'activité. París: SEVPEN.

- (Traducción castellana, más completa) (1974): Las Filipinas y el Pacífico de los ibéricos. Siglos XVI, хVII y хVIII (Estadísticas y Atlas). México DF: Instituto Mexicano de Comercio Exterior.

Chirino, P. (2000) [c. 1610): Història de la provincia de Filipines de la Companyia de Jesús, 1581-1606. Barcelona: Pòrtic. Edición completa, transcrita y comentada por Jaume Górriz.

Conpuz, O. D. (1997): An Economic History of the Philippines. Manila: University of the Philippines Press.

Escobedo Mansilla, R. (1979): El tributo indígena en el Perú (siglos XVI-XVII). Pamplona: EUNSA y O.E.I.

GarcíA-ABÁsolo, A. (1982): «La expansión mexicana hacia el Pacífico: la primera colonización de Filipinas (1570-1580). Historia Mexicana xxxII-125, pp.65-67.

Grau y Monfalcón, J. (1866) [1637]: «Relación del procurador general de la ciudad de Manila e islas Filipinas a S.M., sobre la conservación de estas y sobreseimiento en la cobranza de cierto impuesto a las mercaderías que van a Nueva España», en L. de Torres Mendoza (ed.), Colección de documentos inéditos relativos al descubrimiento, conquista y organización de las antiguas posesiones españoles de América y Oceanía, sacadas de los archivos del Reino, y muy especialmente del de Indias, por [...], abogado de los tribunales, exdiputado a Cortes. Madrid, tomo VI, pp. 345-485. También en Álvarez de Abreu (1977) [1736], tomo 2, pp. 220-320 y, en versión inglesa, en Blair y Robertson, eds. (1903-1909), tomo 27, p. 55-212.

Hidalgo Nuchera, P. (1995a): Encomienda, tributo y trabajo en Filipinas (1570-1608). Madrid: Universidad Autónoma de Madrid-Ediciones Polifemo.

- (1995): Los primeros de Filipinas. Crónicas de la Conquista del Archipiélago de San Lázaro. Madrid: Miraguano Ediciones / Ediciones Polifemo.

Marichal, C. y Souto, M. (1995): «La Nueva España y el financiamiento del Imperio español en América: los situados para el Caribe en el siglo xviII, ponencia presentada al Congreso El situado en el Imperio colonial español. Cartagena de Indias (Colombia), Agosto de 2003 (en prensa).

MartíneZ de ZúÑIGA, J. (1803): Estadismo de las islas Filipinas. Sampaloc, 2 vols.

Miranda, J. (1952): El tributo indígena en la Nueva España durante el siglo XVI. México D.F.: El Colegio de México (existe reedición de 1980).

Morga, A. DE (1997) [1609]: Sucesos de las Islas Filipinas. Madrid: Ed. Polifemo. Edición de Patricio Hidalgo, que incorpora las notas de las ediciones de José Rizal (1890), y W. Retana (1909). 
Ollé, M. (2000): La invención de China. Percepciones y estrategias filipinas respecto a China durante el siglo XVI. Wiesbaden: Harrassowitz Verlag.

Pastells, P. (1926): «Historia General de Filipinas», en P. Torres Lanzas (ed.) (1925-1934), Catálogo de los documentos relativos a las Islas Filipinas existentes en el Archivo de Indias de Sevilla. Barcelona: Compañía General de Tabacos de Filipinas, tomo II.

RodríGuez, I. (1978): Historia de la provincia agustiniana del Ssmo. Nombre de Jesús de Filipinas., Manila: Arnoldus Press, vol. xIII.

San Agustín, G. DE (1975) [1698]: Conquistas de las Islas Filipinas [...], Madrid, CSIC. Edición, introducción y notas de Manuel Merino.

Torres Mendoza, L. DE (1866): Colección de documentos inéditos relativos al descubrimiento, conquista y organización de las antiguas posesiones españoles de América y Oceanía. Madrid, tomo VI.

Zialzita, F. N. (2001): «Land Tenure among Nonhispanized Filipinos», en J. T. Peralta (ed), Reflections on Philippine Culture and Society. Festschrift in Honor of William Henry Scott. Quezon City: Ateneo de Manila University Press, pp. 107-132.

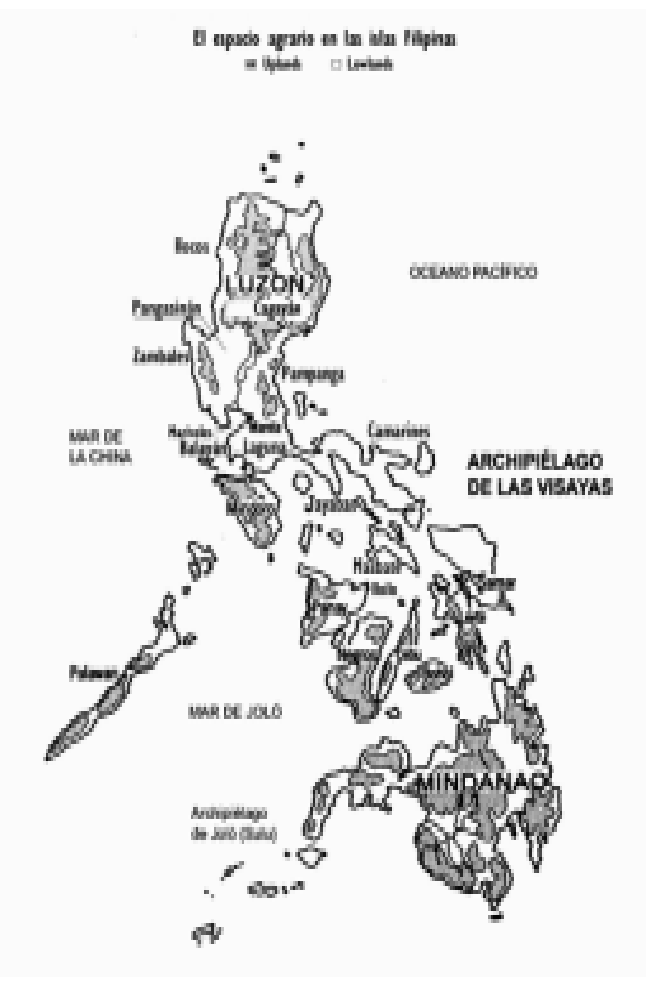


